\title{
O Processo de Bolonha 1.0 e 2.0 e sua Globalização: implicações para a universidade
}

\author{
Lucídio Bianchetti* \\ Universidade Federal de Santa Catarina \\ Lara Carlette Thiengo** \\ Universidade Federal de Santa Catarina
}

Resumo Objetivamos analisar o movimento de transformação da universidade europeia, a partir da implementação do Processo de Bolonha (PB 1.0), considerando seus antecedentes, dentre os quais a Magna Charta Universitatum e a Declaração da Sorbonne e continuidades por meio do PB 2.0 e especialmente a instituição do Programa Horizonte 2020. Investigamos também como a difusão deste Processo/modelo veio globalizando-se em um movimento denominado de 'Globalização do PB'. Essas iniciativas são reações dos líderes europeus, que visam resgatar a hegemonia que a Europa veio perdendo no tocante à liderança e à atração que suas universidades exerciam, bem como na perda do protagonismo em termos econômicos, políticos, culturais e principalmente no quesito inovação em Ciência \& Tecnologia. Utilizamo-nos da análise documental, como metodologia, buscando ter presente a totalidade do processo histórico, na perspectiva de que a compreensão de fatos, acontecimentos, episódios, fenômenos somente pode ser alcançada em seu processo constitutivo. Pela análise percebe-se que o $\mathrm{PB}$, em suas diferentes fases, representa movimentos distintos e complementares de um mesmo processo. Em termos de universidade ficam evidentes as iniciativas e concretizações direcionadas à integração, homogeneização e diferenciação, em âmbito regional, mas que gradativamente vem globalizando-se. A radicalização do PB significa a subsunção da universidade aos desígnios do mercado, colocando em xeque a concepção de universitas, com claros prejuízos, particularmente à formação humana.

PALAVRAS-CHAVE: Processo de Bolonha; Universidade e mercado; Globalização. 
The Bologna Processes 1.0 and 2.0 and their Globalization: Implications for Universities

Abstract This article analyzes the transformation of European universities considering the implementation of the Bologna Process (PB 1.0) and its antecedents, including the Magna Charta Universitatum and the Sorbonne Declaration, and its continuation through Bologna Process 2.0, particularly through the Horizon 2020 program. We also investigate the diffusion of this process and model in a movement known as the "Globalization of the Bologna Process". These initiatives are reactions of European leaders who want to restore Europe's hegemony in the leadership and attraction that its universities had, as well as a loss of command in economic, political and cultural terms, particularly in relation to innovation in science and technology. The methodology involved a document analysis, in an effort to consider the entire historic process, from the perspective that the comprehension of the facts, events, episodes and phenomenon can only be attained in their constitutive process. The analysis indicated that the different phases of the Bologna Process represent different and complementary movements of a single process. Initiatives are evident at universities that are aimed at integration, homogenization and differentiation on a regional level, but which have gradually been globalizing. The radicalization of the Bologna Process has signified the subsumption of universities to the designations of the market, questioning the concept of universitas, while clearly causing harm, particularly for education.

KEYWORDS: Bologna Process; University and market; Globalization.

\section{Situando a problemática em questão}

Do ponto de vista da história tradicional, linear, com predominância de fatos, decisões legislativas etc., o Processo de Bolonha (PB) é um evento localizado e que pode ser descrito com relativa facilidade, na medida em que a referência for um episódio demarcado temporal e geograficamente e que, com o passar do tempo, novos acontecimentos e decisões vieram-lhe sendo agregados e, no seu corpus, implementados. Nesta perspectiva o PB constitui-se em uma "Declaração", assinada conjuntamente por 46 ministros da educação de países que compunham a União Europeia (UE) ${ }^{1}$. Em termos formais, a "Declaração de Bolonha" contém propostas de reorganização ou criação de um novo modelo de universitas, bem como a explicitação de metas, de intencionalidades dos signatários no sentido de transformar uma série de propostas relacionadas à necessidade de as universidades europeias que assinaram o "Pacto" serem submetidas a um aggiornamento, a fim de, entre outros objetivos, resgatarem, juntamente com o conjunto das universidades da UE, a hegemonia de que gozaram quase milenarmente. 
Do ponto de vista histórico-educacional, de quem procura ter presente o processo de totalidade de um acontecimento, de um processo histórico, contudo, o parágrafo acima, ou essa narrativa factual, não passa de um documento, que de fato e de direito, marca o ponto de chegada e de partida, de um processo complexo, eivado de desafiadores nós teóricos e empíricos, demandando um esforço dos pesquisadores para ultrapassar as aparências obnubiladoras desse "Acordo" que deu origem e constitui o também chamado "Pacto de Bolonha". Isto é, na perspectiva de Kosik (1976), a compreensão de fatos, acontecimentos, episódios, fenômenos somente pode ser alcançada em seu processo, em sua constituição se a pergunta voltar-se não para o que ele [PB] é, mas sim, como foi e vem sendo constituído. Desta forma, o desafio é transformar as palavras, expressões, os elementos constitutivos, enfim o conteúdo do parágrafo inicial deste texto em links e envidar esforços no sentido de, via investigação e reflexões, fazer emergir o hipertexto a fim apreender a dialética do processo. Ao empreendermos este esforço compreensivo perceberemos que o significado do $\mathrm{PB}$ e as expectativas em relação ao porquê de sua organização e funcionamento vão muito além da criação do "Espaço Europeu de Educação Superior" (EEES) ${ }^{2}$.

Reproduzimos a título de percepção da complexidade da temática, um excerto de entrevista concedida por Josep M. Blanch, quando faz menção ao PB, já implantado:

Este projeto tem uma dupla face: a manifestamente acadêmica, que pretende integrar, unificar e estandardizar o ensino superior europeu para facilitar a mobilidade dos estudantes, e a efetiva integração europeia ao nível universitário e do mercado de trabalho. E também tem uma face econômica, que consiste em tornar operativas as consignas e recomendações emanadas do Banco Mundial, do Fundo Monetário Internacional e da Organização Mundial do Comércio, que, em nome da sustentabilidade financeira da universidade, propõem sutilmente a 'economização', a mercantilização, a empresarialização e o gerenciamento da universidade, com o pretexto de que é necessário 'modernizá-la', 'desburocratizá-la' e 'abri-la ao mercado'. Porém, paralelamente a esta retórica se vai introduzindo um discurso tecnológico e tecnocrático que vai impondo pautas, critérios e condições financeiras, técnicas, materiais e culturais, colocando no centro do sistema valores como eficiência, produtividade, competitividade, rentabilidade, análise custo-benefício, avaliação por resultados, gestão por objetivos. Enfim, toda a retórica sobre a universidade sucumbe eclipsada por esta nova retórica economicista e managerialista, que vai entrando como por uma porta lateral. Em terceiro lugar, Bolonha significa também um produto final, em forma de modelo de organização universitária, de planos de estudo, de créditos, papéis, protocolos didáticos e de avaliação, conteúdos homologáveis etc. Em uma palavra: uma universidade boa e bonita (se supõe), barata (University "Low Cost", com menos anos, menores custos), rápida (uma espécie de "Fast University", na qual se faça o mesmo em menos anos), estandardizada (Universidade "McDonaldizada", mesmo formato em diferentes espaços), financeiramente sustentável (graduação barata e curta, rápida, para a massa, e mestrado pago para a elite) e mercantilmente adaptada. Dessa forma, em nome de uma universidade europeia pós-moderna nos encontramos com professores e alunos trabalhando mais em menos tempo e com os mesmos meios (BIANCHETTI, 2010, p. 270-1). 
Esta manifestação evidencia um quadro complexo da instituição universidade que emerge do $\mathrm{PB}$ e que não se explica, nem se compreende e muito menos se justifica se o olhar dos pesquisadores se fixarem em um momento e em fatos ou memorandos oficiais. É em função disto que se torna imperioso fazer os dados falarem, buscando apreender o processo em seu movimento mais amplo, no conjunto daquilo que estamos denominando de PB 1.0, iniciado em 1999 e antecedentes, com conclusão prevista para 2010. Em continuidade, é feita a avaliação pela UE e o processo é estendido até 2020 (PB 2.0). Neste contexto, também é lançado o maior programaquadro de financiamento da UE, o Programa Horizonte 2020 (H2020), sobre qual também apresentamos algumas análises preliminares, o que torna necessário, uma vez que as transformações das universidades europeias repercutiram e repercutem fortemente para além do continente europeu, atingindo globalmente as Instituições de todos os países, como veremos posteriormente.

\section{A Europa e a globalização: o eurocentrismo em xeque}

Em termos gerais, a movimentação, as iniciativas de autoridades de países europeus em geral e dos responsáveis pelas instituições universitárias (IES) em particular - colocando aqui em relevo o $\mathrm{PB}$ - relaciona-se à constatação que, a partir da segunda metade do século XX, veio tornando-se cada vez mais evidente que a Europa, em termos de mundo ocidental judaico-cristão, progressivamente vinha perdendo a hegemonia de que havia gozado por séculos em todos os campos.

A globalização, a transnacionalização, a mundialização, que se tornaram realidades a partir do predomínio do modo de produção capitalista ${ }^{3}$, em sua fase monopolista, minaram as bases das fronteiras e fizeram erodir os pilares que sustentaram por tanto tempo o eurocentrismo, deslocando para outras partes do mundo os polos dinâmicos que até então eram constituídos pelo conjunto de países da Europa. Esse deslocamento deu-se, particularmente para a América do Norte (Estados Unidos da América) e para o Sudeste Asiático (Japão), que passaram a ser os polos dinâmicos e hegemônicos do capital.

O processo de globalização implementado pelo sistema vigente, entendido como um modo de produção material e espiritual (IANNI, 1992), abrangeu hegemonicamente toda a dinâmica e todas as manifestações da humanidade no tocante à economia, à política, à cultura, à religião e, como não podia deixar de ser, à educação. É neste aspecto que Mészáros (2006, p. 263) afirma que "nenhuma sociedade pode perdurar sem seu sistema próprio de educação".

É nesse mercado-mundo, que a Europa percebe-se perdendo a concorrência, particularmente para os EUA e vê na educação, em especial na reorganização da universidade, uma oportunidade do resgate ou de 'retornar ao jogo' como protagonista. Neste contexto, a questão da organização da UE como um antídoto para a perda da hegemonia e da competitividade em relação, particularmente aos EUA, passa a ser uma espécie de obsessão dos dirigentes europeus. E decisões, medidas passam a ser tomadas a fim de concretizar esta 'viragem' por parte da Europa. 
Percebemos assim que a Europa, como uma espécie de gigante, se deu conta que estava semiadormecido e que precisava acordar para recuperar o terreno perdido e (re)assumir o protagonismo que a havia caracterizado por tanto tempo. Para tanto, nas frentes econômicas e políticas, apostará na estratégia da UE a fim de criar um espaço comum, com eliminação de entraves aduaneiros, com unificação monetária, com flexibilização do mercado de trabalho e uma série de medidas que concretizariam os "Estados Unidos da Europa"4. De outra parte, um investimento pesado na reorganização da universidade, de tal forma que voltasse a ser atrativa e que estivesse aberta ao livre trânsito de discentes e pesquisadores, que se relacionasse mais fluidamente com o setor produtivo, enfim, que contribuísse para a concretização da almejada "Europa do conhecimento". É a este último aspecto que nos dedicaremos agora a fim de recuperar alguns antecedentes da "Declaração de Bolonha", documento orientador da reorganização da universidade europeia e que, gradativamente vai tornar-se paradigma para iniciativas em relação à (re)organização e funcionamento de universidades para além das fronteiras europeias.

\section{Antecedentes do Processo de Bolonha}

Neste item, sumariamente apontaremos para duas reuniões, das quais resultaram documentos que são considerados precursores mais imediatos do "Processo" ou da "Declaração de Bolonha". Trata-se da "Magna Charta Universitatum" e da "Declaração da Sorbonne”.

\section{"Magna Charta Universitatum"}

No dia 18 de setembro de 1988 os reitores das universidades europeias reuniram-se em Bolonha e após discussões, sintetizaram o resultado em uma "Charta" ${ }^{\prime}$ que foi publicada, estruturalmente assim organizada: inicia com um "Preâmbulo", segue com "Considerandos", em seguida explicitam-se os "Princípios Fundamentais" e conclui-se com "Os meios" previstos para a concretização da proposta sintetizada no documento.

Reproduzimos o "Preâmbulo", por considerar que contém elementos importantes em temos do contexto e daquilo que se (pré)anuncia em relação à universidade:

Os Reitores das Universidades Europeias, abaixo assinados, [...] quatro anos antes da abolição definitiva das fronteiras comunitárias, na perspectiva de uma colaboração alargada entre todos os povos europeus e acreditando que os povos e os Estados devem mais do que nunca tomar consciência do papel que as universidades serão chamadas a desempenhar numa sociedade que se transforma e se internacionaliza cada vez mais...

Nos "Considerandos" os reitores retomam a ideia da importância da "verdadeira" universidade para o futuro da humanidade, dado seu papel em termos de contribuição para o desenvolvimento cultural, científico e tecnológico e seu lócus estratégico como centro de cultura, conhecimento e investigação. Destacam também as contribuições da Instituição na difusão do conhecimento e de suas responsabilidades 
na formação contínua das atuais e futuras gerações, na preparação para a vida em geral e no papel que ela pode desempenhar em uma relação adequada com o meio ambiente.

Em termos de "Princípios" básicos para que isto seja assegurado às universidades, os signatários reivindicam que as Instituições sejam autônomas, "independentes da autoridade política e do poder econômico", que possam ensinar e investigar com liberdade, que a tolerância e o diálogo sejam a marca da relação docentes-discentes na busca do conhecimento.

Em relação aos "Meios", preconiza-se que todos os membros da universidade possam dispor do necessário para que a instituição cumpra suas funções; que o ensino e a investigação sejam concebidos e executados inseparavelmente; que os discentes tenham a liberdade assegurada e que possam contar com condições adequadas para buscar, onde quer que seja, os conhecimentos que desejarem e por fim, consideram os signatários que o progresso e o desenvolvimento está condicionado ao livre fluxo das informações entre as Instituições, bem como da realização de projetos conjuntos.

$\mathrm{Na}$ sequência explicitam a necessidade de as universidades encorajarem a mobilidade de professores e alunos, espelhando-se na livre movimentação de discentes e docentes característica das universitas medievais. Da mesma forma que consideram imprescindível que se garantam equivalências de estatutos, títulos e exames e subsídios para que os estudantes se sintam estimulados a alargarem sua formação via estágios, frequência a atividades em instituições diversas daquelas nas quais estão matriculados.

Cabe assinalar que, ao analisar a "Charta" fica-se com a impressão de que os reitores são protagonistas de um processo no qual o seu papel e as funções que defendem ser a justificativa histórica da existência da universidade, estão preservados/ as. Na verdade, estas questões do protagonismo dos dirigentes universitários e o papel da universidade sofrerão, pouco tempo depois, com a implementação do PB 1.0, uma inflexão sem precedentes na quase milenar história da universidade. Assim, como assinalam Bianchetti e Magalhães (2015), a "Charta" foi um dos últimos estertores do protagonismo dos reitores e o quanto e o como a universidade perde sua função de universitas, em termos gerais e sua autonomia como instituição e gradativamente passa a ser mais uma das organizações ${ }^{6}$ a serviço do mercado globalizado.

\section{A "Declaração da Sorbonne"}

Como parte das comemorações do $800^{\circ}$ ano de fundação da Universidade de Paris, no dia 25 de maio de 1998, os Ministros encarregados da Educação Superior da Alemanha, França, Itália e do Reino Unido elaboram e divulgam aquela que veio a ser conhecida como a "Declaração da Sorbonne" . A partir do reconhecimento que a UE obteve, muitos progressos em função da implantação e funcionamento desta, alertam para o fato de que a Europa não é somente a do "Euro, da banca e da economia". Insistem na necessidade de que a "Europa do saber" não pode ser secundada, particularmente depois de as universidades europeias terem contribuído tanto, inclusive servindo de modelo, no decorrer do tempo, para outras Instituições do mundo todo. 
$\mathrm{Na}$ sequência fazem uma revisão do quanto às universidades contribuíram para a construção e difusão do saber e de como, no decorrer da história, a mobilidade, a livre circulação de mestres e discípulos foi uma das suas características marcantes. Avançam no sentido de que as grandes transformações, seja no mundo da educação seja do trabalho, gerando a necessidade da formação permanente, tornam premente iniciativas no sentido de atender essas novas demandas. Porém, essas iniciativas devem visar o conjunto da UE, devem ser atrativas na direção de "abolir fronteiras" no esforço de tornar de fato aquilo que já havia sido declarado de direito: a constituição e o funcionamento da UE. Um dos meios projetados para tal intento, na área educacional, foi a proposição do "espaço europeu aberto ao ensino superior". Com isto se abriria espaço para a mobilidade discente, visando criar oportunidades para que os estudantes pudessem ter a experiência de vivenciar outras culturas, dominar outras línguas, apropriar-se das chamadas novas tecnologias, avançar enfim na conquista da desejada internacionalização, seja das instituições, seja da formação dos universitários. Como estratégia para oficializar esta mobilidade ${ }^{8}$, com suas tantas vantagens previstas, foi necessário pensar em maneiras de garantir, de fato e de direito, a equivalência de créditos frequentados em universidades de diferentes Estados da UE.

Para tanto a "Declaração" explicita pela primeira vez aquilo que viria a ser implementado como "Transferência de Créditos", consagrado pela expressão em língua inglesa: "European Credit Transfer Sistem" (ECTS), a fim de garantir o reconhecimento internacional dos diplomas. Com esta iniciativa garantir-se-ia a "legibilidade dos diplomas", o que seria um fator facilitador da mobilidade discente.

Previa-se ainda, na "Declaração", que após a licenciatura, o discente poderia optar por "um diploma mais curto de mestrado e um doutoramento mais longo, mantendo pontes estreitas entre um e o outro. Nos dois diplomas, daremos relevo, como convém, à pesquisa e ao trabalho individual". Para habilitar-se a esses diplomas, os estudantes necessariamente precisariam frequentar, pelo menos, um semestre em universidades de Estados da UE diferentes aos de suas origens.

Os ministros também comprometeram-se a avançar na promoção de acordos entre as universidades a fim de garantir a "harmonização progressiva das estruturas conjuntas dos nossos diplomas e dos nossos ciclos de estudo", utilizando como base as experiências já feitas e aquelas em andamento.

Por fim é explicitada a necessidade de um esforço para a criação do "espaço europeu de ensino superior" (aqui ainda em minúscula, pois o EEES era somente uma proposta). E os quatro ministros concluem a "Declaração" conclamando os outros estados membros da UE e outros países da Europa não integrantes da União, a se juntarem "a nós neste objetivo e a todas as universidades europeias para dar lugar à Europa no mundo, melhorando todos os dias, a educação oferecida aos seus cidadãos".

\section{O Processo de Bolonha}

No dia 19 de junho de 1999, os Ministros da Educação Superior europeus, conjuntamente assinaram a "Declaração de Bolonha". Da época até os dias atuais, são 
diversas as denominações que fazem referência a ela: "Pacto", "Acordo", "Processo" etc. Porém a mais consagrada e universal forma de referir-se ao documento é "Processo de Bolonha" (PB), justamente porque é um marco de chegada de outros documentos e propostas intergovernamentais, mas ao mesmo tempo é um ponto de partida de um "processo", que foi implantado e que, a partir de 1999, veio sendo aprimorado, acrescido de iniciativas que não estavam contempladas no original. Esta abertura do leque de 'responsabilidades' que passaram a ser agregadas ao original (que denominaremos de $\mathrm{PB}$ 1.0) veio dando-se por meio das reuniões bienais realizadas pelos ministros da Educação Superior da UE e que tinha no ano de 2010 o prazo limite para sua implementação.

O documento do PB (1.0) inicia fazendo um retrospecto do que havia sido proposto em outros e alcançado até 1999 por parte dos Estados Membros da UE. Deste ponto em diante, contudo a "Declaração" é perpassada por um tom que parte das constatações a respeito da importância do proposto anteriormente para as prescrições e do que é necessário ser feito para a concretização, por exemplo, da compatibilidade e comparabilidade entre os sistemas de ensino superior, de tal forma que se chegue a um modelo único (framework) ou universal para a UE, a fim de poder-se falar em globalização, garantida pela eliminação de quaisquer empecilhos à atratividade/ mobilidade de docentes e discentes. É a partir dessa mudança no tom do documento que começam a aparecer manifestações como:

"É preciso dar apoio através da promoção de medidas concretas para que se avance em passos reais". E menciona-se que para tanto, em reunião anterior contou-se "com a participação de peritos e estudiosos avalizados, vindos de todos os países europeus e deu-nos sugestões muito úteis sobre as iniciativas a tomar". E, confirmando que se passou para o estágio de execução reforça-se que: "Teremos que fixar-nos no objetivo de aumentar a competitividade no Sistema Europeu do Ensino Superior" (EEES) ${ }^{9}$, coordenar políticas, aumentar a atração. Na sequência projeta-se o período de dez anos para concretizar a criação do EEES e sua "promoção mundial".

O sistema implantado foi dividido em duas partes: pré-licenciatura, com duração de três anos. Além de uma formação que equivaleria ao bacharelado, esta fase é pré-requisito para ingressar na segunda - pós-licenciatura - e é considerada um "nível apropriado para ingressar no mercado de trabalho Europeu". A pós-licenciatura abarca o mestrado (dois anos) e o doutorado (três anos). Decide-se também pela implementação do ECTS, com o objetivo de incentivar a mobilidade dos estudantes. E agrega-se uma novidade: "Os créditos poderão ser obtidos em contextos de ensino não-superior, incluindo aprendizagem feita ao longo da vida, contando que sejam reconhecidos pelas Universidades participantes".

Além dos estudantes, prevê-se e incentiva-se também a mobilidade de professores, pesquisadores e pessoas vinculadas a funções administrativas a fim de que melhorem sua qualificação, garantindo-se que a mobilidade não prejudicará "seus direitos estatutários". Uma das estratégias também será o incentivo e a implementação de projetos interinstitucionais de cooperação a fim de contribuir com o avanço na direção de unificação do EEES. 
Após uma série de prescrições no sentido da unificação para caminhar para um sistema único de Ensino Superior na UE, os ministros signatários do PB, ressalvam que isto será feito levando-se em conta a "diversidade das culturas, línguas, sistemas de ensino nacionais e a autonomia das universidades". E concluem a "Declaração" afirmando estarem convencidos de que a criação do EEES "necessita de constante apoio, supervisão e ajustamento às necessidades em permanente evolução" e, frente a isto decidem que vão reunir-se "novamente dentro de dois anos para avaliar o progresso alcançado e decidir sobre os novos passos a serem dados".

Passando da "Declaração de Bolonha", para sua concretização, além da realização de reuniões bienais ${ }^{10}$ de avaliação e tomadas de decisão sobre novos aspectos a agregar ao "Processo", foi criado o Bologna Follow-up Grup - BFUG (Grupo de Acompanhamento de Bolonha), como iniciativa conjunta dos Estados componentes da UE e/ou que aderiram ao "Processo". Porém, internamente também cada Universidade instituiu grupos de trabalho cujo compromisso era Making Bologna Works (Fazer Bolonha funcionar).

Porém, em termos de iniciativas, talvez a mais significativa no que diz respeito à mudança do tom de análise e proposições para o de prescrições na relação entre os documentos precursores e a "Declaração de Bolonha", seja o fato que resultou de uma reunião em Lisboa, no ano de 2000, por parte do Conselho Europeu, um dos mais representativos órgãos políticos da UE. Foi a partir desta reunião, que passou a ser denominada de "Estratégia" ou "Tratado de Lisboa", que, de forma explícita ao "Processo de Bolonha" são atribuídas responsabilidades ou incumbências, envolvendo as universidades, que extrapolam o âmbito da Educação, da cultura e adentram outros campos, abrindo-se espaço para a economia, a política, enfim, à concretização de iniciativas por meio das quais buscam garantir a formatação dos "Estados Unidos da Europa". O PB foi o instrumento para uma guinada na forma de organização e funcionamento da universidade, como veremos no próximo item.

No final de 2009 e início de 2010, a partir das avaliações feitas concluiu-se que grande parte dos objetivos do PB haviam sido alcançados, mas que o "Processo" precisava ser mantido e aprofundado, uma vez que, embora considerado um sucesso, continuava inconcluso frente aos novos desafios que a UE precisava enfrentar. A decisão decorrente foi no sentido de projetar mais dez anos, portanto, projetar para 2020 a data limite para a implantação daquele que passamos a denominar de Processo de Bolonha 2.0.

\section{Processo de Bolonha (2.0) e o Programa Horizonte 2020}

O documento intitulado Processo de Bolonha 2020: o Espaço Europeu do Ensino Superior na nova década foi publicado em 2009, a partir do Comunicado de Louvain (COMISSÃO EUROPEIA, 2009), resultado do primeiro Fórum Político sobre o $\mathrm{PB}$, que envolveu, além dos então 46 países participantes do Processo, outros 20, de fora do continente europeu. Segundo Silveira (2016), a referida Conferência/ Comunicado defende que a internacionalização da educação deve ser regida por normas e diretrizes europeias, em consonância com as orientações da Organização para a 
Cooperação e Desenvolvimento Econômico (OCDE) e da Organização das Nações Unidas para a Educação, a Ciência e a Cultura (Unesco), tendo como foco a modernização das políticas nacionais e a concretização da reforma neoliberal de ensino superior na Europa. Reafirmam-se, assim, os fundamentos do PB como basilares para a implementação da contrarreforma da educação superior até 2020 na Europa ${ }^{11}$.

Vale destacar que, de acordo com a Comissão Europeia, este processo inscreve-se nos objetivos do Quadro estratégico para a cooperação europeia no domínio da Educação e da Formação ${ }^{12}$ e do Europa $2020^{13}$ (COMISSÃO EUROPEIA, 2010), como uma possível política pública para o ensino superior nesses países, especialmente, incentivando os Estados-Membros e as IES a aumentarem a cooperação e a mobilidade com países da própria UE e de fora dela, o que ocorre, principalmente, por meio do Programa Quadro de Financiamento Horizonte 2020 (H2020).

O Programa H2020 funciona como um instrumento financeiro para a implementação da União da Inovação, iniciativa emblemática, no contexto do PB 2.0, destinada a assegurar a competitividade global da Europa, fazendo "coro" ao postulado pelos documentos anteriores que embasavam as propostas do PB 1.0 e 2.0.

Objetiva-se, com este Programa, que não apenas o conhecimento, mas a investigação é um investimento no futuro que deve estar no centro do plano da UE, a fim de promover o crescimento econômico e a geração de empregos. Nesta direção, o argumento apresentado pela Comissão Europeia está fundamentado no entendimento de que, ao associar investigação à inovação, o H2020 contribui com a promoção da excelência científica, a liderança industrial e a resolução de desafios sociais, sendo estes os três pilares ${ }^{14}$ do Programa.

Importante destacar que o orçamento destinado ao Programa H2020 está projetado em aproximadamente 80 bilhões de euros, e o acesso dos países ao financiamento é realizado com base em convites concorrenciais - chamadas abertas por áreas/ temas -, em que podem concorrer universidades, institutos de pesquisa e empresas, preferencialmente, em parcerias. Sobre este tema, é importe frisar que, de acordo com dados da própria Comissão, os programas de trabalhos publicados até a última chamada (COMISSÃO EUROPEIA, 2015a) cobrem um número limitado de áreas, de modo a permitir a concentração de esforços e de recursos, sob o argumento de maximizar o seu impacto.

Primordialmente, o objetivo apresentado pelo Programa é: assegurar que a Europa produza ciência de nível mundial, elimine as barreiras e facilite a colaboração entre os setores público e privado na promoção da inovação, a partir estratégias inovativas em áreas estratégicas. Para isso, com o H2020, visa-se "unir os esforços de instituições de investigação de excelência e congêneres de desempenho inferior para criar ou desenvolver centros de excelência" (COMISSÃO EUROPEIA, 2014, p. 16). 


\section{Do PB 1.0 à versão 2.0 e o Programa Horizonte 2020: inte- gração, internacionalização e o horizonte da 'excelência'}

Promover a UE como destino de estudo e investigação para 'os melhores talentos de todo o mundo' pode ser considerado um dos principais objetivos do Programa H2020. Neste sentido, o Programa prevê o favorecimento de relações internacionais - como, por exemplo, promover facilidades e direitos para os cidadãos que migrarem para a UE, bolsas, entre outras - com o intuito de ampliar o reconhecimento acadêmico, reter talentos e promover o mercado da mobilidade acadêmica. Sendo assim, a centralidade da internacionalização e a atratividade de estudantes de outros países deve ser compreendida a partir de dois campos: concentração de talentos e movimentação de recursos. De acordo com o documento (COMISSÃO EUROPEIA, 2013, p. 9):

O peso econômico do ensino superior internacional está aumentando rapidamente. Alguns países, incluindo destinos populares como o Reino Unido, o Canadá, os EUA e a Austrália, atribuem grande importância ao ensino superior enquanto serviço gerador de uma importante fonte de rendimentos (8,25 mil milhões de libras esterlinas no Reino Unido e 15,5 mil milhões de dólares australianos na Austrália em 2010) [...]. (destaque nosso).

Neste contexto, a Comissão Europeia (2013) destaca que, se desejam continuar a ser o principal destino em um contexto de concorrência crescente por parte da Ásia, do Médio Oriente e da América Latina, as IES europeias terão de agir de forma estratégica para explorar todos os benefícios do prestígio da Europa em termos de excelência do ensino superior. Isso significa que

[as instituições de educação superior] terão de tornar-se ainda mais atrativas, promover ativamente a mobilidade internacional dos alunos e do pessoal, propor currículos inovadores de qualidade mundial e um excelente nível de ensino e oportunidades de investigação, e participar na cooperação e em parcerias estratégicas com outras IES, as entidades governamentais, o setor privado e a sociedade civil de todo o mundo. Além disso, terão de contribuir de forma mais significativa para o crescimento econômico, encorajando a inovação e garantindo que o ensino superior responda às necessidades do mercado de trabalho (COMISSÃO EUROPEIA, 2013, p. 10). (destaque nosso).

Igualmente, esta questão é reforçada pelo relatório (COMISSÃO EUROPEIA, 2017b) elaborado pelo ex-chefe da OMC e do Instituto Delors, Pascal Lamy, no qual se recomenda um relaxamento das regras que regem a participação internacional, de modo que países ricos e estrangeiros possam aderir ao programa com maior facilidade.

No que tange à centralidade da inovação presenteno Programa, no âmbito do pilar 'Liderança Industrial' passa a ser oferecido acesso a capital de risco e financiamento para pequenas e médias empresas 'altamente inovadoras', uma vez que, de acordo com a Comissão Europeia (2010, p. 15), é preciso "levar boas ideias ao mercado". Desse modo, no processo de seleção desses projetos, os proponentes precisam 
demonstrar como a exploração dos resultados gerará o impacto esperado e contribuirá para a economia europeia.

Entendemos, pois, que a ênfase na inovação tecnológica proposta e operacionalizada no H2020 está articulada à necessidade de redução dos custos e tempo, no contexto de crise capitalista, para a retomada dos níveis de acumulação e reversão da taxa decrescente de lucros. Por isso, a universidade é requisitada a atrelar-se mais estreitamente às necessidades de áreas estratégicas do setor produtivo ${ }^{15}$, ainda que a cooperação seja apresentada de modo articulado ao discurso de responsabilidade social e até mesmo com um tom humanitário, resguardando elementos que a associam à tradição social-democrata europeia. Sendo assim, a regulação dos sistemas de educação superior está sendo subsumida a esta racionalidade ao buscar maior rendimento e maior produtividade definidos a partir de matrizes e parâmetros únicos.

A centralidade na inovação indica para o lugar da universidade, ou pelo menos algumas delas, enquanto espaço de pesquisa, motivo pelo qual o nível de doutorado assume especial relevância nos objetivos da UE. De acordo com Haug (2012), é possível notar que os estudos de doutoramento estão se europeizando de forma rápida, em um contexto de crescente cooperação e concorrência entre universidades e países, o que favorece o mercado da mobilidade acadêmica e também a criação de centros de excelência formados por universidades, empresas e institutos de diferentes EstadosMembros do Bloco.

Tendo em vista o exposto, compreendemos que as universidades europeias vêm sendo transformadas (e se transformando) em componente basilar de um sistema de inovação adequado às estratégias de desenvolvimento europeu, a partir da pesquisa e da exploração dos seus resultados, da cooperação industrial e da formação e atração de pesquisadores altamente qualificados (MOROSINI, 2006).

Cabe ainda destacar que, no âmbito da gestão, o H2020 é orientado pela simplificação de regras, gestão financeira e execução, deslocando o foco da verificação dos insumos para a monitorização do desempenho e dos resultados, abrangendo todo o ciclo de vida do projeto, incluindo novas formas de auditoria.

Assim, como apresentado por KRÜGER et al (2017), entendemos que no âmbito da passagem do Estado Educador para Estado Avaliador há uma tendência pautada em um novo equilíbrio entre autonomia e financiamento, associando, cada vez mais, indicadores e contratos de desempenho ao provimento de recursos e também à presença de mecanismos de financiamento adicionais para orientar o sistema. $\mathrm{O}$ H2020 incorpora essa lógica, ao selecionar projetos com base na excelência, estabelecer 'contratos', gerenciar resultados, além de funcionar como um incentivo financeiro para encorajar fusões institucionais e a concentração em áreas de pesquisa, associando de modo explícito a relação desempenho-financiamento.

E ainda, o próprio financiamento diferenciado, posto em prática por meio de projetos direcionados a determinados grupos, e não às IES, também podem ser considerados elementos que enfraquecem as relações institucionais mais amplas, criando movimentos de competitividade entre e intra instituições, entre e intra docentes. 
Sobre os modelos flexíveis de gestão e a autonomia das universidades, destaca-se a mudança do regime de contratação dos docentes, que, cada vez mais, deixam de ser contratados como funcionários públicos e passam a trabalhar sob regime de contratação temporária. Esta questão está diretamente articulada à ênfase na mobilidade e à atração de 'talentos' uma vez que, para que a atração e a retenção desses 'cérebros' ocorra com sucesso, deve existir a prerrogativa para a criação de salários competitivos e a possibilidade de atualização constante do quadro de profissionais.

Os processos de gestão das IES europeias estão cada vez mais profissionalizados, ou seja, há uma tendência que defende que os cargos administrativos das universidades devem ser ocupados por profissionais especializados (em administração ou áreas correlatas), podendo ou não ser membros do corpo docente. Em vista disso, os órgãos colegiados têm cada vez menos 'peso' nas decisões universitárias, uma vez que são considerados exemplos de 'burocracia acadêmica'.

Tendo em conta o caráter processual da questão analisada, consideramos que H2020 'coroa' o longo processo de relativização de determinada universidade europeia, instaurando/reforçando uma concepção de universidade altamente diferenciada, elitista, essencialmente articulada ao setor privado e às demandas produtivas, de modo a endossar um consenso sobre a excelência acadêmica e científica.

Compreendemos que a Comissão Europeia preconiza a concentração das capacidades e competências de formação avançada, bem como a produção científica, em um número restrito de universidades ou de redes integradas, a serviço das grandes corporações de base europeia, deixando na retaguarda um grande número de estabelecimentos de ensino superior para atender a outras atribuições sociais e econômicas diferenciadas. Como afirma Barrera (2015), trata-se de estabelecer uma diferença explícita entre a educação para as massas (graduação) e uma educação de qualidade reservada ao sistema de pós-graduação de algumas instituições, espaço em que a pesquisa está concentrada.

De acordo com Nóvoa (2015), poder-se-ia argumentar que o processo de europeização da educação superior é estranho e irônico, ao passo que os cidadãos dos países menos desenvolvidos, sobretudo a partir do H2020, passam a pagar a ciência que se faz nos países mais desenvolvidos. Sobre este ponto, o autor elucida:

\footnotetext{
É desnecessário dizer que tudo é feito de acordo com os melhores "padrões internacionais", legitimados com linguagens e métricas de excelência, inovação e competitividade, empreendedorismo, transferência de conhecimento e mérito tecnológico, outputs, produtividade e impacto. Mas o problema está precisamente aqui. Em nome da europeização, reproduzem-se as mesmas fraturas de sempre. (NÓVOA, 2015, p. 269)
}

Essa divisão de classes do ensino universitário expressa uma forma de "desmontagem da universidade pública” (NEWFIELD, 2008 apud BARRERA, 2015, p. 45) a partir do modelo estadunidense de Universidade de Classe Mundial difundido pelo Banco Mundial (SALMI, 2009), que passa a ser o grande referencial para as universidades europeias (e também fora da UE) na atualidade, como alertam pesquisas recentes (SILVA JÚNIOR, 2017; THIENGO, 2018). 


\section{Elementos conclusivos: implicações para o ser/fazer universidade}

A título de elaborar alguns elementos para finalizar este artigo, embora compreendendo que tratamos de programas e tendências em movimento, é importante destacar que ao passo que o $\mathrm{PB}$ (1.0 e 2.0) é orientado no sentido de criar uma plataforma integrada e homogeneizada para as universidades europeias, o H2020 vem criando uma forma de diferenciação distinta (que não o perfil sócio histórico das IES europeias), baseado na constituição de algumas instituições 'de ponta' (ou conjunto destas.) de modo a diferenciarem-se das demais.

Todavia, sinalizamos que se trata de processos distintos e complementares, parte de um mesmo movimento, mais amplo, de transformação da universidade europeia, uma vez que o $\mathrm{PB} 1.0$ e o $\mathrm{PB} 2.0$ conferem as bases, em termos de integração regional, para que programas como o $\mathrm{H} 2020$ pudesse ser implementado. Isso significa que na inexistência de um sistema integrado e homogêneo seriam impraticáveis ações como germinar/criar redes de IES com potencial de excelência, ou criar redes de excelência de nível internacional em áreas temáticas e em parceria com o setor produtivo, e até mesmo intensificar a mobilidade acadêmica e a atratividade europeia.

Ademais, cabe salientar que ambos os movimentos (tentativas de integração/homogeneização e diferenciação para a excelência) tem ganhado força para além da UE, como, por exemplo, com o lançamento da Universidade em Rede do BRICS ${ }^{16}$ ou Projeto Tunnig ${ }^{17}$, no âmbito do Mercosul, o que demonstra a relevância do Bloco europeu no âmbito da governança supranacional da educação, uma vez que difunde visões de mundo, modelos e experiências que têm repercussões diretas nas formas de pensar e fazer educação (GREK, 2016), especialmente, em relação à América Latina.

Neste mesmo sentido, cabe destacar que BRICS e Mercosul, preservadas suas especificidades, evidenciam similitudes com a UE ao buscar produzir e organizar o consenso, bem como direcionar política e as reformas dos sistemas nacionais de educação superior com vistas à comparabilidade, reconhecimento de créditos e mobilidade acadêmica entre os distintos sistemas nacionais de educação superior (SILVEIRA, 2016). Isso acontece, de acordo com Dale (2004), porque os agrupamentos regionais partilham a preocupação com o controle e concordam sobre certas regras.

Além disso, as reformas da educação superior iniciadas principalmente no final do século XX constituem um processo que não pode ser "pensado como um fato de um único país, pois se trata de um movimento mundial, com as especificidades históricas de cada contexto, que mantém traços de identidade em todos eles segundo a racionalidade da transição do metabolismo social capitalista" (SILVA JÚNIOR, 2003, p. 71). É neste contexto que se materializam as constatações e até denúncias de Dale (2001), ao detectar uma "agenda globalmente estruturada para a educação" e Robertson (2009) ao enfatizar que o PB, de uma iniciativa europeia, transformou-se em um processo globalizado.

Assim, tratar da 'globalização' de Bolonha e das variadas nuances desse processo dentro e fora da UE, significa abordar o processo de descaracterização de 
um tipo de universidade, que passa por uma série de transformações responsáveis por refluir até as funções primordiais desta instituição, sendo estas cada vez mais negligenciadas e secundadas, especialmente, no que se refere à formação humana.

\section{Referências}

BARRERA, J. C. B. La tentacion del rey Midas: para una economia politica del conocimiento. Madrid, Espanha: Siglo XXI, 2015.

BIANCHETTI, L. O Processo de Bolonha e a intensificação do trabalho na universidade: entrevista com Josep M. Blanch. Educação \& Sociedade (Impresso), Campinas, CEDES, v. 31, n. 110, p. 263-285, 2010.

BIANCHETTI, L.; MAGALHÃES, A. M. Declaração de Bolonha e internacionalização da educação superior: protagonismo dos reitores e autonomia universitária em questão. Avaliação, Campinas; Sorocaba, SP. V. 20, n. 1, p. 225-249, mar. 2015.

CHURCHILL, W. Memórias da Segunda Guerra Mundial. São Paulo: Companhia das Letras, 2017. Volume 2 (1941-1945).

COMISSÃO EUROPEIA. The Bologna Process 2020 - The European Higher Education Area in the new decade (Comunicado de leuven/louvain-la-neuve), Bologna, Espanha: [s.n], 2009. Disponível em: <http://www.uc.pt/ge3s/pasta_guia_ge3s/Leuven_Louvain-la-Neuve_ Communiqe29_April_2009.pdf>.Acesso em: 10 fev. 2018.

COMISSÃO EUROPEIA Europa 2020 - Estratégia para um crescimento inteligente, sustentável e inclusivo. Bruxelas, Bélgica: [s.n], 2010. Disponível em: <http://www.poci-compete2020. pt/admin/fileman/Uploads/Documents/Estrategia_europa2020.pdf>. Acesso em: 20 fev. 2018.

COMISSÃO EUROPEIA. Horizonte 2020: Comissão propõe um investimento de $80 \mathrm{mil}$ milhões de euros em investigação e inovação para estimular o crescimento e o emprego. Comunicado de imprensa. Bruxelas, Bélgica, 30 nov. 2011. Disponível em: <http://europa.eu/rapid/ press-release_IP-11-1475_pt.htm>. Acesso em: 15 ago. 2016.

COMISSÃO EUROPEIA. Memorando. Horizonte 2020 - novo programa de investigação e inovação da UE. Bruxelas, Bélgica, 03 de dezembro de 2013. Disponível em: <http://europa.eu/ rapid/press-release_MEMO-13-1085_en.htm.>. Acesso em: 10 maio 2017.

COMISSÃO EUROPEIA. Horizonte 2020 em breves palavras. Bruxelas, Bélgica, 2014b. Disponível em: <https://ec.europa.eu/programmes/horizon2020/sites/horizon2020/files/ H2020_PT_KI0213413PTN.pdf>.Acesso em: 3 set. 2016.

COMISSÃO EUROPEIA. Horizon 2020 - First results. Bruxelas: RTD, 2015a. 47 p. Disponível em: <https:/ec.europa.eu/programmes/horizon2020/sites/horizon2020/files/horizon_2020_first_results.pdf >. Acesso em: 10 ago. 2017.

COMISSAO EUROPEIA. Investing in the European future we want. European Union, 2017. Brussels: Publications Office of the European Union, 2017b. Acesso em: 21 fev. 2018.

CONSELHO EUROPEU. Educação e Formação para 2020. Bruxelas, 2009. Disponível em: <http://eur-lex.europa.eu/legal-content/PT/TXT/?uri=LEGISSUM:ef0016.>. Acesso em: 10 set. 2017.

DALE, R. Globalização e educação: demonstrando a existência de uma "cultura educacional mundial comum" ou localizando uma "agenda globalmente estruturada para a educação"? Educação, Sociedade \& Culturas. Porto, UP/FPCE/CIIE, n. 16, p. 133-169, 2001.

DALE, R. Globalização e educação: demonstrando a existência de uma "Cultura Educacional Mundial Comum" ou localizando uma "Agenda Globalmente Estruturada para a Educação"?

Educação \& Sociedade, Campinas, v. 25, n. 87, maio/ago. 2004. p. 423-460. 
FIÚZA DE MELLO, A. Globalização, sociedade do conhecimento e educação superior. Os sinais de Bolonha e os desafios do Brasil e da América Latina. Brasília: Editora da UnB, 2011.

GARCIA MONJÓN, J. V (Coord.). Hacia el espacio europeo de educación superior. El reto de la adaptación de la universidad a Bolonia. Oleiros (La Coruña): netbiblos, 2009.

GREK, S. Atores do conhecimento e a construção de novos cenários de governança: o caso da direção-geral de educação e cultura da Comissão Europeia. Educação \& Sociedade, Campinas, v. 37, n. 136, p. 707-726, jul./set. 2016.

HAUG, G. Políticas de Aseguramiento de la Calidad en la Educación Superior Europea. In: LEMAITRE, M. J.; ZENTENO, M. E. (Editores.). Aseguramiento de la Calidad en Iberaoamérica. Educación Superior - Informe 2012. Santiago, Chile: RLI, p. 74-89, 2012.

IANNI, O. A sociedade global. Rio de Janeiro: Civilização Brasileira, 1992.

KOSIK, K. Dialética do concreto. 2 ed. Rio de Janeiro: Paz e Terra, 1976.

KRÜGER, H. G. et al. La reforma de la gobernanza en los sistemas universitarios europeos: Los casos de Austria, Dinamarca, Finlandia, Francia, Países Bajos y Portugal. Fundación CYD. Barcelona: EPA Disseny, 2017.

MARX, K. Elementos fundamentales para la crítica de la economia política (Grundrisse). Borrador 1857-1858. 12 ed. México: Siglo Veintiuno Editores, 1989.

MĖSZÁROS, I. A teoria da alienação em Marx. São Paulo: Boitempo, 2006.

MOROSINI, M. (Org.). A universidade no Brasil: concepções e modelos. Brasília: Ipea, 2006. $297 \mathrm{p}$.

NÓVOA, A. Em busca da liberdade nas universidades: para que serve a pesquisa em educação? Educ. Pesqui., São Paulo, v. 41, n. 1, p. 263-272, mar. 2015. Disponível em: <http://www. scielo.br/scielo.php?script=sci_arttext\&pid=S1517-97022015000100263\&lng=pt\&nrm=iso $>$. Acesso em: 17 dez. 2017.

ROBERTSON, S. L. O processo de Bolonha da Europa torna-se global: modelo, mercado, mobilidade, força intelectual ou estratégia para construção do Estado? Revista Brasileira de Educação, Rio de Janeiro, Campinas: ANPEd e Autores Associados, v. 14, n. 42, p.. 407-422, set./dez. 2009.

SALMI, J. E1 desafío de crear universidades de rango mundial. Colômbia: Mayol Ediciones/ Banco Mundial, 2009.

SILVA JÚNIOR, J. R. Reformas do Estado e da educação e as políticas para a formação de professores a distância: implicações políticas e teórica. Revista Brasileira de Educação, Rio de Janeiro, n. 24, p. 78-94, 2003.

SILVA JR., J.R. The New Brazilian University. A busca por resultados comercializáveis: para quem? Bauru: Canal6editora, 2017.

SILVEIRA, Z. Mercosul educacional e reforma da educação superior no Brasil. In: CONFERÊNCIA FORGES, 6. Campinas, 28 a 30 nov. 2016. Anais eletrônicos... Lisboa: Universidade de Lisboa, p. 1-13, 2016.

THIENGO, L.C. Universidades de Classe Mundial e o consenso pela excelência: tendências e manifestações globais e locais. 2018. 366f. Tese (Doutorado em Educação). Programa de PósGraduação em Educação da Universidade Federal de Santa Catarina (UFSC), Florianópolis, 2018.

\section{Notas}

${ }^{1}$ A "Declaração de Bolonha" foi assinada pelos ministros da educação de 46 países, representados pelos seus respectivos ministros da educação. Deste total de países, 30 deles faziam, à época, parte da UE. Algu- 
mas nações pertencentes ao Bloco não foram signatários do PB, como foi o caso de Kosovo e Quirguistão. Outros pleiteavam fazer parte da UE, porém não foram aceitos por não preencher requisitos considerados imprescindíveis para compor o Bloco. No corrente ano de 2018, compõem a UE 28 países. O caso da saída do Reino Unido, embora decidido por votação, ainda está em processo de implementação.

${ }^{2}$ Posteriormente foi criado também o "Espaço Europeu de Investigação" (EEI).

${ }^{3} \mathrm{Na}$ metade do século XIX Marx (1989) alertava para o fato de que "el capital, por su naturaliza, tende a superar toda barrera espacial [...] el capital por um lado debe tender a arrasar toda barrera espacial opuesta al tráfico, id est al intercambio, y a conquistar toda la Tierra como su mercado..." (p. 12 e 31). Na mesma perspectiva, quase um século e meio depois, Ianni (1992, p. 55), concebe o capitalismo como um "modo de produção material e espiritual, forma de organizar a vida e o trabalho, ou processo civilizatório, que se expande contínua e reiteradamente pelos quatro cantos do mundo".

${ }^{4}$ Interessante que esta, hoje, é uma expressão corrente para caracterizar a UE. Seus primeiros esboços, contudo, já estavam presentes nos discursos de Wiston Churcheill (1874 - 1975), na década de 1940, como se pode observar em sua autobiobrafia (CHURCHILL, 2017).

${ }^{5}$ Cf. www.magna-charta.org/resources/files/the-magna-charta/portuguese. Acesso em 07 de março de 2018.

${ }^{6}$ A distinção entre instituição e organização, no tocante à universidade é objeto de análise do texto de Chauí (2003).

7 Cf. https://sigarra.up.pt/feup/pt/noticias_geral.noticias_cont?p_id.../Sorbonne.pdf. Acesso em 07 de março de 2018.

${ }^{8}$ Àquela altura a mobilidade, embora não na proporção desejada para a concretização da UE, já era garantida para discentes e docentes, via projetos com financiamento, dentre os quais são exemplares o "Projeto Sócrates" (para professores) e, para estudantes, o "Projeto ERASMUS" (European Action Scheme for the Mobility of University Students).

${ }^{9}$ No livro/coletânea "Hacia el Espacio Europeo de Educación Superior”, organizado por Monjón (2009), encontra-se uma das mais completas explicitações e análises de como as universidades vieram adaptando-se a Bolonha.

${ }^{10}$ Essas reuniões, que sempre eram concluídas com um "Comunicado", passaram a ser regulares a partir de 2001. Assim, no PB 1.0, registram-se cinco "Comunicados": De Praga (2001), de Berlim (2003), de Bergen (2005), de Londres (2007), de Leuven/Lovain-la-Neuve (2009). Os “Comunicados” seguem mais ou menos o mesmo esquema: avaliam o que foi alcançado e agregam novas iniciativas ampliando o escopo e o leque das proposições iniciais do $\mathrm{PB}$.

${ }^{11}$ Todavia, é na Conferência de Budapeste/Viena (2010) que o PB entra efetivamente em uma nova etapaa 2.0 diríamos-, uma vez que, nesta Conferência, foi (re)lançado oficialmente o EEES - o que indica, para a Comissão, o cumprimento do objetivo maior da Declaração de Bolonha. No entanto, como a existência do EEES não esgota os objetivos do $\mathrm{PB}$, este entra em uma nova fase de consolidação e de operacionalização. Na Etapa 'Bolonha 2020' também foram realizadas outras duas Conferências, nas quais foram elaborados os Comunicados de Bucareste (2012) e Everan (2015). Nestes últimos, dentre as questões discutidas e políticas implementadas, destaca-se a proeminência da mobilidade internacional

${ }^{12}$ Renova o Quadro Estratégico para Educação e Formação 2010. De acordo com o documento legislativo do Quadro estratégico para a cooperação europeia no domínio da Educação e da Formação 2020 (CONSELHO EUROPEU, 2009), este visa estabelecer uma estreita articulação com o PB, apoiando a modernização 
dos sistemas de educação superior europeus e a garantia de qualidade, reconhecimento, mobilidade e transparência, bem como a pertinência de estabelecer uma cooperação intersetorial entre as iniciativas lançadas pela UE em matéria de educação, formação e em domínios que lhes estejam associados.

${ }^{13}$ Substitui a "Estratégia de Lisboa" e reforça a tendência de intensificação da europeização por intermédio do reforço da governança comunitária e intergovernamental, bem como está fundamentada na promoção de uma 'economia baseada no conhecimento', o que significa tratamento pragmático para o desenvolvimento e para a inovação. Nessa lógica, a maior capacidade de investigação e o desenvolvimento de inovação em todos os setores resultaria na melhora da competitividade e na criação de empregos.

${ }^{14} \mathrm{O}$ pilar 'Excelência Científica' é orientado a partir de uma série de áreas programáticas, visando apoiar ideias novas e com risco elevado, de forma a acelerar o desenvolvimento em áreas emergentes da ciência e da tecnologia, bem como a construção de novas tecnologias futuras. Para tanto, além de impulsionar a competitividade, considera-se apoiar abordagens novas e não convencionais, investigação fundamental, pesquisas de longo prazo e de inovação tecnológica em temas selecionados e pesquisa voltada para objetivos, enfrentando-se assim os grandes desafios da área de Ciência \& Tecnologia, com investimentos diretos em infraestruturas de investigação e financiamento para infraestruturas físicas e eletrônicas de classe mundial, acessíveis a todos os investigadores. No pilar 'Liderança Industrial', ganha centralidade a investigação no domínio das tecnologias ditas essenciais e a facilitação do acesso a capitais de risco para investigação e inovação. O pilar 'Desafios Societários', por sua vez, é apresentado como meio de oferecer respostas às grandes preocupações dos cidadãos europeus, a saber: saúde, crescimento demográfico e bem-estar; segurança alimentar, agricultura sustentável e proteção das florestas, investigação marinha e marítima e bioeconomia; energia segura, limpa e eficiente; transporte inteligente, verde e integrado; ação climática, recursos eficientes e matérias-primas; sociedades inclusivas e inovadoras; sociedades seguras.

${ }^{15}$ É importante assinalar que parte do orçamento do H2020 é direcionado ao financiamento do Instituto Europeu de Tecnologia às atividades de investigação realizadas no âmbito da pesquisa do Tratado Euratom e também ao Centro Comum de Investigação (Joint Research Centre ).

${ }^{16}$ Programa lançado em 2015 para promover uma rede de excelência no âmbito da Pós-Graduação, a partir de áreas estratégicas do Brasil, Rússia, Índia, China e, mais recentemente, a África do Sul.

${ }^{17}$ É um projeto independente que procura "afinar" as estruturas educativas da América Latina à luz do Processo de Bolonha. Cf. http://tuning.unideusto.org/tuningal/index.php?option=com_frontpage\&Itemid=1.

* Professor doutor da Universidade Federal de Santa Catarina, Florianópolis, Santa Catarina, Brasil.

** Doutora em Educação pela Universidade Federal de Santa Catarina, Florianópolis, Santa Catarina, Brasil.

\section{Correspondência}

Lucidio Bianchetti - Universidade Federal de Santa Catarina, Centro de Ciências da Educação, Departamento de Estudos Especializados em Educação. Campus Universitário, s/n, Trindade. CEP: 88010-970. Florianópolis, Santa Catarina, Brasil.

E-mail: lucidio.bianchetti@pq.cnpq.br-laracarlette@gmail.com

Recebido em 30 de março de 2018

Aprovado em 28 de maio de 2018 